\title{
Do we need more long-term outcome trials for the treatment of hypertension?
}

\author{
${ }^{1}$ DG Beevers, ${ }^{2} \mathrm{GT}$ McInnes \\ ${ }^{1}$ Emeritus Professor of Medicine, Centre for Cardiovascular Sciences, City Hospital, Birmingham; ${ }^{2}$ Professor of Clinical Pharmacology, Institute \\ of Cardiovascular and Medical Sciences, University of Glasgow, Glasgow, UK
}

\begin{abstract}
The epidemiology of arterial hypertension and its treatment has been underlined by a huge research literature. Consistently raised arterial blood pressure in a clinic or home setting is a simple clinical observation that marks a predilection to a variety of fatal and non-fatal vascular disease events. Over the past 50 years tolerable, safe and effective primary and secondary medicines to offset a substantial amount of the associated morbidity and mortality risk of elevated blood pressure have emerged. Due to the nature of the population-relative risk and low absolute risk of this phenomenon it has often taken very large numbers of patients recruited from multiple centres in several countries and huge financial investment to define these profiles. Few national clinical research funds have invested in this process and it has often been left to a relatively small group of investigators to work closely with the commercial producers of new medicines to complete the essential outcome trials on which much of contemporary cardiovascular medical practice is based.
\end{abstract}

Currently there are few, if any, significant new drug entities relevant to raised blood pressure under development. Most of the underlying clinical management principles and associations are clear. Achieved blood pressure, through patient adherence and variable prescriber practice, defines outcomes for individuals. The theoretical likelihood of a major step forward in the understanding of raised arterial blood pressure or a preferred means for population management is low. Moreover, with few new drug entities, investment in major outcome trials is unlikely to be proposed and the target for new trials is perhaps less apparent.

While there can be no doubt that few areas in recent medical practice have benefited more from such huge achievements in underlining treatment, is it time to move on from the cardiovascular mega trial in hypertension? In this controversy we have asked two international authorities in blood pressure care to address the case for and against further mega trials in this area of practice.

KEYWORDS Cost, desirability, feasibility, hypertension, long-term trials

DECLARATION OF INTERESTS Professor Beevers was a participant in several longterm trials in hypertension, including MRC-I, SYST-EUR, LIFE and ASCOT.

\author{
Correspondence to \\ DG Beevers, \\ Ascot Clinic, City Hospital, \\ Birmingham BI8 7QH, UK
}

tel. +44 (0) I 2 I 5075080

e-mail gareth.beevers@swbh.nhs.uk

GT Mclnnes,

Institute of Cardiovascular

and Medical Sciences, University

of Glasgow, Gardiner Institute,

44 Church Street,

Glasgow GII 6NT, UK

tel. +44 (0)14I 2112319

e-mail

gordon.mcinnes@glasgow.ac.uk

\section{The case against further mega trials}

\section{DG Beevers}

Systemic hypertension is the world's most common chronic medical condition where long-term drug treatment has been shown to be beneficial. It is becoming more common as more and more people live longer, a phenomenon which in part is due to the earlier treatment of raised blood pressure in middle age. Thus as many as $75 \%$ of people over the age of 75 years have levels of blood pressure where drug treatment is worthwhile.' The sheer logistics and financial cost of hypertension and its treatment means that we must be absolutely certain that the treatment we recommend is genuinely necessary. Consideration must, however, be given to the risk-benefit ratio (anxiety, inconvenience and drug side effects versus the reduction of heart attack and stroke risks) as well as the cost-benefit ratio (numbers needed to treat and the financial cost per lives saved versus heart attacks and strokes prevented).

When it comes to a consideration of the issues listed above, hypertension is a near unique condition in that there is no lack of information. There have been a large number of long-term epidemiological follow-up studies in defined populations providing accurate assessments of cardiovascular risk associated with any level of blood pressure. ${ }^{2}$ Furthermore, a great many well-conducted controlled trials have provided reliable information on the value of the drug treatment of hypertension and a comparison of the benefits of the different drug classes. ${ }^{3}$ This is only right and proper in the light of the numbers of people concerned and the corresponding healthcare costs. 
Specialists in almost all other specialties must be envious of the amount of information we have on hypertension and its treatment.'Hypertensionology' is a very evidencebased specialty. The question arises as to whether we need more information on the value of antihypertensive treatment. The answer is intuitively 'yes', on the grounds that we certainly will never have all the answers. The problem is that the information we need may never become available because of the problems of feasibility and cost. The purpose of this review is briefly to discuss what we know and what further long-term outcome data we would like to have and then to consider whether it will ever be feasible to obtain them.

\section{LONG-TERM TRIALS OF THE VALUE OF ANTI- HYPERTENSIVE TREATMENT COMPARED WITH NO TREATMENT}

\section{Hard endpoint trials}

The first long-term outcome trial of the value of antihypertensive drug therapy was conducted in Chelmsford, Essex. ${ }^{4}$ It was initiated in 1958 and published in The Lancet in 1964. It was an open-label comparison of drug therapy compared with no treatment in 61 men and women with severe hypertension. Initially the active therapy was with the ganglion-blocking drug pentolinium and the post-ganglionic adrenergic blockers guanethidine and bethanidine, which had intolerable side effects, and when the thiazide diuretics and methyldopa became available, these were substituted. ${ }^{5}$ The trial clearly showed that antihypertensive treatment for severe hypertension did prevent strokes.

The first randomised placebo-controlled trial was from the US Veterans' Administration and was published in two parts in 1967 and 1970.6,7 The trial was confined to men. Since then about 13 further large randomised trials have been published, concentrating on the milder grades of hypertension and patients with isolated systolic hypertension in their $60 \mathrm{~s}$ and $70 \mathrm{~s}$. What is almost certainly the last such trial, examining the value of antihypertensive treatment in patients over the age of 80 years, was published in $2008 .^{8}$ It is now unethical to withhold active drug therapy from patients with hypertension on a long-term basis.

So what more information do we need? The most important question in $201 \mathrm{I}$ is whether drug treatment should be given to patients at a lower cardiovascular risk. Many of these patients will be under the age of 50 years, with systolic blood pressures below $160 \mathrm{mmHg}$. A large proportion will be women in their child-bearing years and it is highly unlikely that any research ethics committee would ever give permission to conduct a long-term cardiovascular outcome trial in this group, even if it were feasible.
Patients with mild hypertension (below $160 / 90 \mathrm{mmHg}$ ) are at such a low absolute cardiovascular risk (below 5\% in ten years), even though they have a high relative risk, that a placebo-controlled drug trial would encounter almost insuperable difficulties. ${ }^{9}$ The currently available outcome trials in higher-risk patients (absolute risk around $20 \%$ in ten years) needed thousands of patients to achieve statistical significance. It follows that in the lower-risk younger patients it would require not thousands but tens of thousands. It is highly unlikely that any organisation could fund such a study. It would have to be conducted on a multicentre, multinational basis, requiring literally thousands of investigators and a large central co-ordinating centre.

But it won't happen. Even if and when the current world economic recession draws to a close, national or international research grant-giving bodies would place a drug trial in low-risk individuals well down on their list of priorities. The pharmaceutical industry likewise would lack interest. Drug company funding of clinical trials in hypertension, as well as educational and scientific meetings, has already started to decline. Questions on the cost-benefit ratio and numbers needed to treat to prevent one heart attack or stroke in low-risk patients would mean that even if such a trial did prove positive statistically, many clinicians and their patients would consider swallowing tablets for years on end to be not worth the inconvenience and cost.

\section{Surrogate endpoint trials}

Surrogate endpoint trials are those where the outcomes are not heart attacks or strokes but instead milder nonclinically evident 'silent' consequences of hypertension. These include the development of left ventricular hypertrophy, microproteinuria, arterial intima/media thickening or central artery stiffness. The problems of conducting outcome trials of this sort are similar to those discussed above. If the patients are at high risk they should be given optimal treatment anyway. If they are at low risk the number developing these softer endpoints would be so small that any clinical trial would have to be large and conducted on a multicentre basis. The techniques for measuring some of these endpoints would need to be carefully standardised among large numbers of investigators as they are heavily observer-dependent and some are expensive.

\section{'Prehypertension'}

Over the past ten years, a new concept has been the focus of interest in some centres. 'Prehypertension' is another name for a 'high normal' blood pressure (130$139 / 80-89 \mathrm{mmHg}$ ) measured in epidemiological surveys. ${ }^{10}$ As blood pressure tends to rise with advancing age, many such individuals will progress to develop pressures above this figure and then be considered to have 'hypertension'. In the Framingham Heart Project, $40 \%$ of 'prehypertensives' under the age of 65 years developed 'hypertension' within five years; $60 \%$ did not." 
This concept has led some researchers to investigate whether antihypertensive drug therapy in 'prehypertension' or in people at high familial risk of developing hypertension, might delay the onset of 'hypertension'. The results have been largely inconclusive. ${ }^{12,13}$ One must question the ethics of labelling people with 'high normal' blood pressures as having a medical condition in the first place. The logic of prescribing antihypertensive drugs to prevent the onset of hypertension and thus obviate the need for antihypertensive drugs seems curious. The cost-benefit ratio for treating this man-made medical condition must surely be enormous if the long-term benefits of treatment are considered to be the prevention of heart disease or strokes. Finally the role of the pharmaceutical industry in sponsoring such research needs to be questioned.

Patients who have 'high normal' blood pressures do need to be rechecked by their doctor more frequently than those whose pressures are 'normal'. They should be advised on the importance of maintaining a healthy diet and lifestyle. But the idea of 'medicalising' them seems to this author to be spurious and possibly harmful. While it is not in the remit of this review, one long-term outcome trial that would be useful and informative would be a randomised trial of dietary and lifestyle intervention compared with no action in people with average blood pressures, those with 'prehypertension' as well as those with the milder grades of hypertension. It is doubtful whether such a study will ever be funded. Tens of thousands of people would need to be followed up so the logistical problems and cost would be prohibitive.

\section{LONG-TERM OUTCOME TRIALS OF DIFFERENT TARGETS IN THE TREATMENT OF HYPERTENSION}

In 2005, the National Heart, Lung and Blood Institute (NHLBI) in the US published a statement proposing that the next generation of long-term outcome trials in hypertension should include an investigation on the optimum target blood pressure to be achieved among treated hypertensive patients. For example, how much benefit in terms of heart attack and stroke prevention is obtained if the systolic blood pressure is reduced to below $130 \mathrm{mmHg}$ compared with a target of 130-150 $\mathrm{mmHg} !{ }^{14}$ The NHLBI report also commented that such a trial would need to be 'funded for at least a decade'. This proposed trial would also investigate the different drug classes. The target blood pressure component of this trial would be a follow-on from the Hypertension Optimal Treatment (HOT) trial which was published in $1998 .^{15}$ In the HOT trial the three target diastolic pressures for treated hypertensives were $<90,<85$ and $<80 \mathrm{mmHg}$.

Every day clinicians are asking themselves: "How low should I lower the blood pressure?' We only have the HOT study to help us. The trial results, while a little inconclusive, strongly suggested that blood pressures reduced to below $140 / 80 \mathrm{mmHg}$ are optimal. In a posthoc analysis of patients participating in the ONgoing Telmisartan Alone and in combination with Ramipril Global Endpoint Trial (ON TARGET) there was a strong suggestion that systolic blood pressures should be reduced to below $130 \mathrm{mmHg} \cdot{ }^{16} \mathrm{~A}$ dedicated outcome trial of different targets for systolic blood pressure reduction, while possibly desirable, is probably not feasible. Given the epidemiological evidence that it is best to have a blood pressure at or around $120 / 80 \mathrm{mmHg}$ and the observational evidence from ON TARGET and other trials, how many clinicians or their patients would be content to maintain a systolic blood pressure of $145 \mathrm{mmHg}$ for years on end simply because they have been randomised to the control group in the proposed NHLBI trial?

\section{LONG-TERM OUTCOME TRIALS COMPARING DIFFERENT ANTIHYPERTENSIVE DRUGS}

The Losartan Intervention For Endpoints (LIFE) trial and the Anglo-Scandinavian Cardiac Outcomes Trial (ASCOT) came up with a finding that may have come as a surprise to some. Both these trials showed that the beta blocker atenolol was less effective than its comparator drugs at preventing strokes. ${ }^{17,18}$ They also showed that these differences were not explained by differences in their ability to lower blood pressure. While most antihypertensive drugs are about equally effective at lowering blood pressure, they are not equally effective at preventing vascular events. Subsequently, in the Avoiding Cardiovascular Events through Combination Therapy in Patients Living with Systolic Hypertension (ACCOMPLISH) trial the calcium channel blocker amlodipine was more effective than hydrochlorothiazide at preventing vascular events when added to a drug regime based on an angiotensin-converting enzyme inhibitor. ${ }^{19}$

One of the consequences of these studies is that we can no longer assume that 'it does not matter how we lower blood pressure'; it does matter. The implications of these findings are that all new classes of blood pressurelowering agents, and possibly all new agents within existing drug classes, need to be tested in long-term cardiovascular outcome trials. It is highly unlikely that such trials would ever be conducted, on the same grounds as stated above: feasibility, cost and loss of interest in hypertension on the part of the pharmaceutical industry. There are currently no long-term outcome data on the use of the direct renin inhibitor aliskiren and the centrally acting imidazoline agonist moxonidine in essential hypertension - and there probably never will be. But clinicians still prescribe them.

Long-term cardiovascular outcome trials in hypertension are very expensive, costing up to $f 100$ million. ${ }^{20}$ The result of this is that it is unlikely that there will be many more. As most of these trials would primarily be designed to 
validate new antihypertensive agents, government grantgiving bodies and the major medical charities are likely to take the view that it is up to the pharmaceutical companies to validate their own new products. Meanwhile, the pharmaceutical houses themselves are unlikely to fund such large trials on financial grounds. Most antihypertensive drugs are now off patent or soon to be so. As soon as drugs go off patent, cheaper generic products become available. Profits from off-patent drugs to the original developer drop quickly. With this simple economic argument in mind, it is naïve to expect the major drug companies to fund major long-term trials.

Furthermore, with the exception of aliskiren, there are no new antihypertensive drugs available or in the offing. The prohibitive cost of the endothelin receptor antagonists bosentan and ambrisentan means that these agents could never be used in the millions of people who need antihypertensive therapy. Their use is likely to be confined to the treatment of severe, life-threatening diseases such as pulmonary arterial hypertension.

\section{REFERENCES}

I Primatesta P, Poulter NR. Hypertension management and control among English adults aged 65 years and older in 2000 and $200 \mathrm{I}$. J Hypertens 2004; 22:1093-8. doi:10.1097/00004872-20040600000008

2 Prospective Studies Collaboration. Age-specific relevance of usual blood pressure to vascular mortality: a meta-analysis of individual data for one million adults in 61 prospective studies. Lancet 2002 ; 360:1903-13. doi:I0.1016/S0|40-6736(02) II9II-8

3 Turnbull F, Neal B, Algert C et al. Blood Pressure Lowering Treatment Trialists' Collaboration. Effects of different blood pressure-lowering regimens on major cardiovascular events in individuals with and without diabetes mellitus. Results of prospectively designed overviews of randomised trials. Arch Intern Med 2005; 165:1410-9. doi:I0.100I/archinte.165.12.1410

4 Hamilton M, Thompson EN, Wisniewski TK. The role of blood pressure control in preventing complications of hypertension. Lancet 1964; I:235-8. doi: I0.1016/S0I40-6736(64)92344-X

5 Hamilton M.The 1964 trial of antihypertensive treatment.J Human Hypertens 2005; 19:503. doi:10.1038/sj.jhh.1001853

6 Veterans Administration Cooperative Study Group on Antihypertensive Agents. Effects of treatment on morbidity in hypertension. I. Results in patients with diastolic blood pressure averaging II5 through 129 mmHg. JAMA 1967; 202:I I6-22.

7 Veterans Administration Cooperative Study Group on Antihypertensive Agents. Effects of treatment on morbidity in hypertension. II. Results in patients with diastolic blood pressure averaging 90 through II4 mmHg. JAMA 1970; 213:1।43-52.

8 Beckett NS, Peters R, Fletcher AE et al. Treatment of hypertension in patients 80 years of age or older. N Engl J Med 2008; 348: 188798. doi:I0.1056/NEJMoa080I369

9 Jackson R. Updated New Zealand cardiovascular risk-benefit prediction guide. BMJ 2000; 320:709-10.

10 Moynihan R. Who benefits from treating prehypertension? BMJ 2008; 34I:c4442. doi:I0.I I36/bmj.c4442

I I Vasan RS, Larson MG, Liep EP et al. Assessment of frequency of progression to hypertension in non-hypertensive participants in the Framingham Heart Study; a cohort study. Lancet 200I; 358:I682-6. doi:I0.I0I6/S0I40-6736(0I)067I0-I

12 Julius S Nesbitt SD, Egan BM et al. Feasibility of treating prehypertension with an angiotensin receptor blocker. $N$ Engl J Med 2006; 354:I685-97. doi:I0.1056/NEJMoa060838
Studies of the effects of new versus old drugs in the prevention or reduction of surrogate endpoints in hypertension are likely to continue. But clinicians will ask themselves whether it is permissible to extrapolate from the short-term surrogate endpoint trials to longterm benefits in stroke and heart attack prevention. Unlike the British Hypertension Society guidelines, the European guidelines continue to endorse the use of beta blockers as suitable for the first-line treatment of uncomplicated hypertension. ${ }^{21}$ They do this on the grounds that, although atenolol was inferior to its comparator drugs in the LIFE and ASCOT trials, celiprolol, bisoprolol and nebivolol do reduce mortality in patients with heart failure. This view seems to this author an extrapolation too far.

In conclusion, long-term cardiovascular outcome trials are ethically justifiable and might possibly influence clinical practice. The problem is that they are not financially feasible. The golden era of massive drug company-funded trials in hypertension is over.

I 3 Skov K, Eiskjaer H, Hansen HE et al. Treatment of young subjects at high familial risk of future hypertension with an angiotensin receptor blocker. Hypertension 2007; 50:89-95. doi:I0.II6I/ HYPERTENSIONAHA.I07.089532

14 The National Heart, Lung and Blood Institute Working Group on Future Directions in Hypertension Treatment Trials. Major clinical trials of hypertension. What should be done next? Hypertension 2005; 46: I-6. doi:I0.II6I/0I.HYP.0000I68924.3709I.58

I5 Hansson L, Zanchetti A, Carruthers SG et al. Effects of intensive blood-pressure lowering and low-dose aspirin in patients with hypertension: principal results of the Hypertension Optimal Treatment (HOT) randomised trial. HOT Study Group. Lancet 1998; 35I:I755-62. doi:I0.10I6/S0I40-6736(98)043 II-6

16 Sleight $P$, Redon J, Verdecchia $P$ et al. Prognostic value of blood pressure in patients with high vascular risk in the Ongoing Telmisartan Alone and in combination with Ramipril Global Endpoint Trial study. J Hypertens 2009; 27:1360-9. doi:10.1097/ $\mathrm{HJH} .0 \mathrm{b0}$ I3e32832d7370

17 Dahlöf B, Devereux RB, Kjeldsen SE et al. Cardiovascular morbidity and mortality in the Losartan Intervention For Endpoint reduction in hypertension study (LIFE) : a randomised trial against atenolol. Lancet 2002; 359:995-1003. doi:10.1016/S0I406736(02)08089-3

18 Dahlöf B, Sever PS, Poulter NR et al. Prevention of cardiovascular events with an antihypertensive regimen of amlodipine adding perindopril as required versus atenolol adding bendroflumethiazide as required, in the Anglo-Scandinavian Cardiac Outcomes TrialBlood Pressure Lowering Arm (ASCOT-BPLA): a multicentre randomised controlled trial. Lancet 2005; 366:895-906. doi:I0.10I6/S0I40-6736(05)67I85-I

19 Janerson K,Weber MA, Bakris GL et al. Benazepril plus amlodipine or hydrochlorothiazide for hypertension in high-risk patients. N Engl J Med 2008; 359:24I7-28. doi:I0.1056/NEJMoa0806I82

20 Poulter NR. Personal communication; 2010

21 Mancia G, De Backer G, Dominiczak A et al. 2007 guidelines for the management of arterial hypertension: the Task Force for the Management of Arterial Hypertension of the European Society of Hypertension (ESH) and of the European Society of Cardiology (ESC). J Hypertens 2007; 25: I I05-87. doi: I0.1097/HJH.0b0 I3e328Ifc975a 


\title{
The case for further mega trials
}

\author{
GT McInnes
}

Large outcome trials have been hugely influential in the management of hypertension. There is no area of medicine where what we do is more founded on high quality, robust data.

\section{EARLY SUCCESSES}

By the mid-1990s, almost 20 unconfounded, prospective, randomised trials comparing antihypertensive therapy (based mainly on thiazide-like diuretics and beta blockers) against placebo-treated or untreated controls in around 50,000 middle-aged or elderly people with mainly diastolic hypertension established the benefit of blood pressure (BP) lowering.' Results were highly consistent. For a mean difference in diastolic BP of $5-6 \mathrm{mmHg}$ (systolic BP 10 $\mathrm{mmHg}$ ) over five years, stroke incidence was reduced by about $40 \%$, coronary heart disease (CHD) $15-20 \%$, all vascular deaths $20-25 \%$ and all-cause mortality $12 \%$. Since events are evenly spaced across trials, the average time to event was 2.5 years. Thus, modest reductions in BP are associated with large proportional reductions in cardiovascular (CV) events over a very short time scale.

Since these early days, the evidence of benefit has extended to those with isolated systolic hypertension ${ }^{2,3}$ and the very elderly. ${ }^{4}$ Reductions in CV outcomes with angiotensin-converting enzyme (ACE) inhibitors and calcium channel blockers as first-line agents are similar to those with diuretics and beta blockers. ${ }^{5}$ More rigorous control of BP is associated with better outcomes. Proportional benefits of treatment are consistent across the BP range; the greater the CV risk, the greater the absolute benefit.

\section{RECENT CONTROVERSIES}

Driven largely by commercial considerations but bolstered by the enthusiasm of some clinicians, newer antihypertensive agents were pitted usually against conventional drugs in several highly expensive large outcome trials. Few convincing net benefits emerged. For instance, calcium channel blockers may have a slight edge in stroke prevention, ${ }^{5}$ but this is offset by lesser protection against heart failure. ${ }^{6}$

Meta-analyses have concluded that the benefits of antihypertensive treatment depend largely on BP lowering, with drug classes having only a minor influence. ${ }^{5,6}$ All BP-lowering agents have similar effects in reducing $\mathrm{CHD}$ and stroke for a given reduction in $\mathrm{BP}$, regardless of pre-treatment BP and existing CV disease.

When the recent comparative clinical trials were designed it was assumed that a small difference in BP between the treatment arms early after randomisation would be acceptable, provided eventual BP control was similar. It is now clear that this was a mistake and such inequalities cloud the interpretation of many trials. For example, the results of the Anglo-Scandinavian Cardiac Outcomes Trial (ASCOT) suggest an advantage of contemporary treatment (calcium channel blocker + ACE inhibitor) over conventional therapy (beta blocker + diuretic), ${ }^{7}$ but an early BP advantage for contemporary therapy persisted throughout follow-up and might entirely explain the outcome advantages. ${ }^{8}$ Similarly, the Valsartan Antihypertensive Long-term Use Evaluation (VALUE) study provides strong evidence for the importance of early BP control in determining eventual $\mathrm{CV}$ morbidity and mortality, at least in high-risk individuals.

Several recent trials have explored the effect of rigorous BP control in high-risk individuals. ${ }^{10-13}$ Despite further reduction in $\mathrm{BP}$, no significant reduction in $\mathrm{CV}$ events was found. These findings challenge epidemiological data that the lower the BP the better..$^{5,14}$

\section{IS IT WHAT YOU DO OR THE WAY YOU DO IT?}

Based on the results of the Heart Outcomes Prevention Evaluation (HOPE) study, ACE inhibition is widely believed to have cardioprotective properties independent of $\mathrm{BP}$ reduction. ${ }^{15}$ However, better $\mathrm{BP}$ control with ramipril compared with control therapy might entirely explain the observed $22 \%$ reduction in CV events. ${ }^{5}$ The dosing schedule in HOPE, where ramipril was administrated in the evening, may have led to an underestimate of daytime BP lowering. A small ambulatory BP monitoring substudy suggests that differences between ramipril and control might be much greater than published. ${ }^{16}$

The Telmisartan Randomized Assessment Study in ACEIntolerant Subjects with Cardiovascular Disease (TRANSCEND) attempted to replicate HOPE using an angiotensin receptor blocker in ACE inhibitor-intolerant people. $^{12}$ Compared with control, BP reduction was similar to HOPE; ${ }^{15}$ the primary outcome was unaffected. TRANSCEND was hopelessly underpowered and a high proportion of participants were taking other cardioprotective therapy.

The Losartan Intervention For Endpoint reduction in hypertension (LIFE) trial, a comparison of losartan and atenolol-based therapy in hypertensive people with electrocardiogram evidence of left ventricular hypertrophy, is unusual in that there was no important difference between the treatment arms in BP control throughout the trial. ${ }^{17}$ Nevertheless, losartan-treated 
patients had significantly fewer CV events, particularly stroke. This finding is somewhat undermined by a metaanalysis which proposes that beta blockers are less effective than other drugs in preventing stroke. ${ }^{18}$ This analysis ignores significant heterogeneity between trials and fails to make adequate allowance for BP differences. Others conclude that the lesser effect of beta blockers in stroke prevention is entirely dependent on comparisons with calcium channel blockers, which have an effect on that endpoint slightly greater than all other drugs. ${ }^{5}$

It appears that what you do is much more important than the way that you do it. This conclusion is a disappointment to those who have criticised older drugs on the basis of inadequate data. ${ }^{19}$ Robust evidence from large outcome trials provide little to support these prejudices.

\section{HYPOTHESES FROM CONTROVERSIES}

The results of many recent outcome trials on hypertension have been inconclusive. However, out of these controversies have come several clinically important hypotheses that need to be tested.

Epidemiologists have noted that the benefits of BP reduction are independent of starting $B$ P. $^{5}$ They propose that it is logical to reduce $\mathrm{BP}$ in all with absolute CV risk which would translate into worthwhile absolute benefit.

Others take the view that a failure of trials comparing antihypertensive drugs or strategies to demonstrate differences is because the inclusion of high-risk individuals meant that the influence of BP reduction was so dominant but differences between treatments were obscured. ${ }^{20}$ The importance of particular pharmacological approaches might be best seen if treatment is restricted to early intervention before $\mathrm{CV}$ disease is apparent. This implies treatment of people with BP levels below current thresholds for intervention. Antihypertensive treatment in such people should prevent progression to overt hypertension, but outcome data are lacking.

Trials of more intensive BP control in high-risk patients did not demonstrate clear-cut benefit. ${ }^{10-13}$ However, these studies were seriously underpowered because of a failure to take into account the cardioprotective effect of concomitant therapy. The event rate in the placebo arm of TRANSCEND ${ }^{12}$ was similar to that in the active arm of HOPE. ${ }^{15}$ Furthermore, the $95 \%$ confidence intervals between the randomised treatments did not exclude a clinically meaningful benefit of rigorous BP control.

While tight control of BP has not consistently been associated with lower CV rates, in general no harm has been demonstrated. However, there must be a J- or U-shaped relationship between BP and mortality since a $\mathrm{BP}$ of zero is incompatible with life. The point of inflection (the level of BP associated with the lowest risk) is unknown and probably varies in different populations. In observational studies, patients with hypertension and established CHD who had an on-treatment diastolic BP less than $85 \mathrm{mmHg}$ had increased risk of death from myocardial infarction while no such J-shaped relationship was seen in those without prior CHD. ${ }^{21,22}$

Similar findings were suggested in a retrospective analysis of data from the International VerapamilTrandolapril Study (INVEST) in people with CHD. ${ }^{23}$ Such retrospective analyses eliminate the benefit of randomisation and may reflect reverse causality. A J-shaped relationship has not been seen in randomised comparisons in patients with high CHD risk despite achieved diastolic BP of $80 \mathrm{mmHg}$ or less. ${ }^{15,24,25}$ Rigorous control of BP in hypertensive patients with CHD was associated with prevention of stroke but no increased risk of cardiac events in the randomised Hypertension Optimal Treatment (HOT) trial. ${ }^{26}$ Despite the poor quality of data supporting a J-phenomenon, concerns about this have impeded effective treatment.

Post-hoc analysis of BP data from VALUE ${ }^{27}$ and $\mathrm{ASCOT}^{7}$ suggest that early BP advantage for one treatment arm is not fully compensated during long-term follow-up by the use of more additional therapy. The initiation of treatment with combination therapy appears to result in better-sustained $\mathrm{BP}^{28}$ Whether early BP control leads to better long-term CV outcomes, as suggested from VALUE,' remains to be established.

\section{FUTURE CHALLENGES}

In the past few years, morbidity and mortality trials in hypertension have been the target of growing dissatisfaction and criticism. ${ }^{20}$ The author advocates greater use of observational data and intermediate (or surrogate) endpoints. This might fulfil the aspirations of the manufacturers of new drugs which have failed to make the expected impact on hard $\mathrm{CV}$ outcomes but have shown 'advantages' for surrogates of uncertain significance. There is also a danger that, as opinion leaders reach the end of their careers, they wish a line to be drawn under the evidence base. To relegate large outcome trials of antihypertensive drug therapy to history along with these opinion leaders would be a tragedy for people with high BP.

Many issues remain to be resolved. The traditional 'start low, go slow' approach to management may be misguided. Failure to control BP by initial therapy may activate compensatory mechanisms which make control more difficult to achieve in the long term. Testing this hypothesis is very difficult, but recent evidence is supportive of the early introduction of combination therapy without increased side effects. ${ }^{28} \mathrm{~A}$ major programme of studies designed by the British Hypertension Society and funded by the British Heart Foundation (PATHWAY) is investigating this and other 
issues. The question of whether better early control translates into better CV outcomes can only be addressed by further long-term outcome trials.

A strategy that addresses not only BP but also other risk factors should have a greater impact on $\mathrm{CV}$ outcomes. The 'polypill' concept suggests that while antihypertensive therapy might reduce $\mathrm{CV}$ risk by $75 \%$, two antihypertensive drugs plus a statin plus aspirin plus folate might reduce risk by more than $80 \%{ }^{29}$ Findings from ASCOT which examined antihypertensive therapy plus statin in people with relatively normal low-density lipoprotein-cholesterol support this hypothesis. ${ }^{730}$ The threshold for intervention would be absolute CV risk rather than BP. However, the devil is in the detail. Current evidence does not support a cardioprotective effect of folate, ${ }^{31}$ while the primary preventive effect of aspirin may be outweighed by excessive risk. A modified 'polypill' approach (multiple antihypertensive drugs + statin) is under evaluation in large-scale trials. ${ }^{32}$

Recent underpowered studies have suggested little if any benefit from rigorous BP targets, even in high-risk individuals. Low BP is seldom achieved, even in clinical trials, ${ }^{33}$ but concerns about harmful effects of rigorous BP control (J-shaped relationship) is a deterrent in clinical practice. There is an urgent need for an adequately powered study. The National Institutes of Health (NIH)funded Systolic Blood Pressure Intervention Trial (SPRINT), which commenced in autumn 2010, is evaluating intensive systolic BP control $(<120 \mathrm{mmHg}$ vs $<140 \mathrm{mmHg})$ in 7,500 high-risk patients, with the primary outcome a composite of $\mathrm{CV}$ events.

An analysis of trial results in an epidemiological context suggests $C V$ benefits from $B P$ lowering regardless of the starting level, particularly in those at high risk. ${ }^{5}$ Currently, the initiation of drug therapy in those with high-normal BP is not supported by good-quality trial evidence. Outcome trials would need to be very large and prolonged but might be enriched by preferential inclusion of those with high baseline BP, diabetes and high left ventricular mass.

Other emerging issues include the most appropriate measurement techniques (office, home, ambulatory, brachial, aortic), visit-visit variability and the influence of heart rate. ${ }^{34} \mathrm{~A}$ more complete assessment of BP responses is needed in future trials. ${ }^{35}$ Even where no important differences in BP between treatment arms are observed, subtle inequalities (e.g. visit-visit variability) may be essential to fully inform clinical practice.
A feature of recent major trials has been the low rate of clinical outcomes and hence statistical power. As a consequence of precision, results have often been inconclusive. Larger study populations are necessary to make allowance for this. To take into account the high background use of other cardioprotective therapies in hypertension trials, substantial differences in BP between treatment arms will be needed to detect a significant difference for composite $\mathrm{CV}$ endpoints. ${ }^{36}$

Despite the many advances in recent decades, there are many unmet needs in hypertension management and more are likely to emerge. Predicting the future is generally a futile exercise. The uncertainties are summarised by one of the great philosophers of the twenty-first century:

There are known knowns; there are things we know we know. We also know there are known unknowns; that is to say we know there are some things we do not know. But there are also unknown unknowns the ones we don't know we don't know.

- Donald Rumsfeld, 2002

These thoughts are insightful but may appear doggerel unless we continue to conduct large outcome trials of antihypertensive drug therapy.

Large outcome trials of antihypertensive therapy are essential to inform clinical practice but are hard to do and expensive. Other than for some landmark trials sponsored by the $\mathrm{NIH}$ in the US or the Medical Research Council in the UK, only the pharmaceutical industry has been willing to provide the funds.

Pharmaceutical companies are unlikely to be willing to continue to make the enormous financial investment without some guarantee of a return. It can be argued that, because of industry involvement, recent trials were poorly designed, focused on issues of commercial interest and resulted in findings that have failed to advance the management of hypertension. However, hypotheses have been generated which should now be evaluated adequately in clinical trials. The pressure is now on national bodies to support well-designed but less expensive trials to address clinically important issues. Further large-scale trials of antihypertensive therapy are needed. The only question is who will provide the funds.

\section{REFERENCES}

I Collins R, MacMahon S. Blood pressure, antihypertensive drug treatment and the risks of stroke and of coronary heart disease. Br Med Bull 1994; 50:272-98.

2 SHEP Co-operative Research Group. Prevention of stroke by antihypertensive drug treatment in older persons with isolated systolic hypertension: final results of the Systolic Hypertension in the Elderly Program (SHEP). JAMA 199I; 265:3255-64. 
3 Staessen JA, Fagard R, Thijs L et al. Randomised double-blind comparison of placebo and active treatment for older patients with isolated systolic hypertension. The Systolic Hypertension in Europe (Syst-Eur) Trial Investigators. Lancet 1997; 350:757-64. doi:I0.I0I6/S0I40-6736(97)0538I-6

4 Beckett NS, Peters R, Fletcher AE et al. Treatment of hypertension in patients 80 years of age or older. N Engl J Med 2008; 358: I88798. doi: I0.1056/NEJMoa080I369

5 Law MR, Morris JK, Wald NJ. Use of blood pressure lowering drugs in the prevention of cardiovascular disease: meta-analysis of 147 randomised trials in the context of expectations from prospective epidemiological studies. BMJ 2009; 338:1245-53. doi: I0.1 I36/bmj. bl 665

6 Blood Pressure Lowering Treatment Trialist Collaboration. Effects of different blood-pressure-lowering regimens on major cardiovascular events: results of prospectively-designed overviews of randomised trials. Lancet 2003; 362:1527-35. doi:I0.10I6/S0|40-6736(03)|4739-3

7 Dahlöf B, Sever PS, Poulter NR et al. Prevention of cardiovascular events with an antihypertensive regimen of amlodipine adding perindopril as required versus atenolol adding bendroflumethiazide as required, in the Anglo-Scandinavian Cardiac Outcomes Trial Blood Pressure Lowering Arm (ASCOT-BPLA): a multicentre randomised controlled trial. Lancet 2005; 366:895-906. doi:I0.1016/ S0I40-6736(05)67I85-I

8 Staessen JA, BirkenhägerWH. Evidence that new antihypertensives are superior to older drugs. Lancet 2005; 366:869-7I. doi:I0.1016/ S0I40-6736(05)67|47-4

9 Weber M, Julius S, Kjeldsen SE et al. Blood pressure dependent and independent effects of antihypertensive treatment in clinical events in the VALUE trial. Lancet 2004; 363:2049-5I. doi:I0.1016/S0I406736(04) I6456-8

I0 ADVANCE Collaborative Group. Effects of a fixed combination of perindopril and indapamide on macrovascular and microvascular outcomes in patients with type 2 diabetes mellitus (the ADVANCE trial) a randomised controlled trial. Lancet 2007 ; 370:829-40. doi:I0.I0I6/S0I40-6736(07)6I303-8

II The ONTARGET Investigators. Telmisartan, ramipril, or both in patients at high risk for vascular events. N Engl J Med 2008; 358:1547-59. doi: 10.1056/NEJMoa0801317

12 TRANSCEND Investigators. Effects of the angiotensin-receptor blocker telmisartan on cardiovascular events in high-risk patients intolerant to angiotensin-converting enzyme inhibitors: a randomised controlled trial. Lancet 2008;372: I I74-83. doi:I0.1016/ SOI40-6736(08)6I242-8

13 Yusuf S, Diener HC, Sacco RL et al. Telmisartan to prevent recurrent stroke and cardiovascular events. N Engl J Med 2008; 359:1225-37. doi: 10.1056/NEJMoa0804593

14 Prospective Studies Collaboration. Age-specific relevance of usual blood pressure to vascular mortality: a meta-analysis of individual data for one million adults in 61 prospective studies. Lancet 2002; 360:1903-13. doi:I0.1016/S0140-6736(02) II9|I-8

15 HOPE (Heart Outcomes Prevention Evaluation) Study Investigators. Effects of an angiotensin-converting-enzyme inhibitor, ramipril, on cardiovascular events in high-risk patients. N Engl J Med 2000; 342: |45-53. doi: I0.1056/NEJM20000|20342030|

16 Svensson P, de Faire U, Sleight $P$ et al. Comparative effects of ramipril on ambulatory and office blood pressure: a HOPE substudy. Hypertension 200I; 38: E28-E32. doi:I0.1 I6I/hyl I0I.099502

I7 Dahlöf B, Devereux RB, Kjeldson SE et al. Cardiovascular morbidity and mortality in the Losartan Intervention For Endpoint reduction in hypertension study (LIFE): a randomised trial against atenolol. Lancet 2002; 359:995-1003. doi:I0.1016/S0I40-6736(02)08089-3

18 Lindholm LH, Carlberg B, Samuelsson O. Should beta blockers remain first choice in the treatment of primary hypertension? A meta-analysis. Lancet 2005; 366:I545-53. doi:I0.I0I6/S0I406736(05)67573-3

19 Messerli FH, Beevers DG, Franklin SS et al. Beta-blockers in hypertension: the emperor has no clothes - an open letter to present and prospective drafters of new guidelines for the treatment of hypertension. Am J Hypertens 2003; 16:870-3. doi:I0.10I6/S0895-706I(03)0I0I7-3

20 Zanchetti A. Evidence-based medicine in hypertension. What type of evidence? J Hypertens 2005; 23:III3-20. doi:10.1097/0I. hjh.0000I70370.4I387.Ib

2I Cruickshank JM, Thorp JM, Zacharias FJ. Benefits and potential harm of lowering high blood pressure. Lancet 1987; I: 58I-4. doi:I0.10I6/S0I40-6736(87)9023I-5

22 Stewart IM. Relation of reduction in pressure to first myocardial infarction in patients receiving treatment for severe hypertension. Lancet I979; I: 86I-5. doi:I0.I0I6/S0I40-6736(79)9I274-I

23 Messerli FH, Mancia G, Conti CR et al. Dogma disputed: can aggressively lowering blood pressure in hypertensive patients with coronary artery disease be dangerous? Ann Intern Med 2006; 144:884-93.

24 EUROPA Investigators. Efficacy of perindopril in reduction of cardiovascular events among patients with stable coronary artery disease: randomised double-blind, placebo-controlled, multicentre trial (the EUROPA study). Lancet 2003; 362:782-8. doi:10.10161 SOI40-6736(03) I4286-9

25 Nissen SE, Tuzcu EM, Libby $P$ et al. Effect of antihypertensive agents on cardiovascular events in patients with coronary disease and normal blood pressure. The CAMELOT Study: a randomized controlled trial. JAMA 2004; 292:2217-26. doi:I0.100I/ jama.292.18.2217

26 Zanchetti A, Hansson L, Clement D et al. Benefits and risks of more intensive blood pressure lowering in hypertensive patients of the HOT Study with different risk profiles: does a J-shaped curve exist in smokers? J Hypertens 2003; 21:797-804. doi: 10.1097/00004872200304000-00024

27 Julius S, Kjeldsen SE, Weber $M$ et al. Outcomes in hypertensive patients at high cardiovascular risk treated with regimens based on valsartan or amlodipine: the VALUE randomised trial. Lancet 2004; 363:2022-3I. doi:I0.I0I6/S0I40-6736(04) I645I-9

28 Brown MJ, Mclnnes GT, Papst CE et al. Aliskiren and the calcium channel blocker amlodipine combination as an initial treatment strategy for hypertension control (ACCELERATE): a randomised, parallel-group trial. Lancet 20I I; 377:3 I2-20. doi: I0.10I6/SOI406736(10)62003-X

29 Wald NJ, Law MR. A strategy to reduce cardiovascular disease by more than $80 \%$. BMJ 2003; 326:1419-23. doi:I0.1I36/ bmj.326.7404.1419

30 Sever PS, Dahlöf B, Poulter NR et al. Prevention of coronary and stroke events with atorvastatin in hypertensive patients who have average or lower-than-average cholesterol concentration in the Anglo-Scandinavian Cardiac Outcomes Trial - Lipid Lowering Arm (ASCOT-LLA): a multicentre randomised controlled trial. Lancet 2003; 36 I: I |49-58. doi: I0.1016/S0 I40-6736(03) I2948-0

3I Mclnnes GT. Antioxidants in hypertension: another false dawn? J Hypertens 2005; 23:1963-6. doi:I0.1097/0I.hjh.0000186834.86867.96

32 Lonn E, Bosch J, Teo KK et al. The polypill in the prevention of cardiovascular diseases: key concepts, current status, challenges and future directions. Circulation 2010; 122:2078-88. doi:I0.1161/ CIRCULATIONAHA.109.873232

33 Mancia G. Role of outcome trials in providing information on antihypertensive treatment: importance and limitations. Am J Hypertens 2006; 19:1-7. doi:10.1016/j.amjhyper.2005.10.009

34 Paul L, Hastie CE, Li WS et al. Resting heart rate pattern during follow-up and mortality in hypertensive patients. Hypertension 2010; 55:567-74. doi:10.1 16I/HYPERTENSIONAHA.109.144808

35 Zanchetti A, Mancia G, Black HR et al. Facts and fallacies of blood pressure control in recent trials: implications in the management of patients with hypertension. J Hypertens 2009: 27:673-9. doi:10.1097/HJH.0b013e3283298ea2

36 Verdecchia P, Gentile G, Angeli F et al. Influence of blood pressure reduction on composite cardiovascular endpoints in clinical trials. J Hypertens 2010; 28: I356-65. doi: I0.1097/HJH.0b0I3e328338e2bb 